\title{
1 Functional dynamics of claudin expression in Japanese \\ 2 medaka (Oryzias latipes): response to environmental salinity
}

4 Maryline C. Bossus ${ }^{1}$, Steffen S. Madsen ${ }^{1,2}$, Christian K. Tipsmark ${ }^{1 *}$

$6 \quad{ }^{1}$ Department of Biological Sciences, University of Arkansas, SCEN 601, Fayetteville, AR 72701,

7 USA

$8{ }^{2}$ Departement of Biology, University of Southern Denmark, Campusvej 55, 5230 Odense M,

9 Denmark

10

11 Running title: Claudin response to salinity in Japanese medaka

13 Ms. has 30 pages, 6 figures, 2 tables

15 "Corresponding author email:

16 Dr. Christian K. Tipsmark

17 Department of Biological Sciences

18 University of Arkansas

19 SCEN 601

20 Fayetteville, AR 72701, USA

21 Tel: +1 4795758436

22 Tipsmark@uark.edu 


\section{Abstract}

2 Salinity regulation of 13 claudin paralogs was investigated in osmoregulatory organs of

3 euryhaline Japanese medaka. They were identified by blast-search in the medaka genome

4 database based on representation in osmoregulatory organs of other teleosts. Our hypothesis was

5 that, because of their sequence similarities to mammalian orthologs previously characterized as

6 barrier- and ion-selective channel-forming proteins, these paralogs would respond to salinity

7 according to expected modulation of osmoregulatory function. Cldn10c, $-10 d,-10 e,-10 f,-27 a,-$

$828 a,-28 b$ and $-30 c$ had 4 - to 100 -fold higher expression in gill than other examined organs. Two

9 splice variants of $c l d n 10 b$ were predominantly expressed in kidney, while $c l d n 15 a$ and $-b$ and -

1025 were found mainly in intestine. In gills, cldn27a, $-28 a,-28 b$ and $-30 c$ did not change between

11 fresh water (FW) and seawater (SW)-acclimated fish, while cldn10c, -10d, -10e, -10f were most

12 abundant in SW. Short-term SW transfer induced up-regulation of $c l d n 10$ gill paralogs after 1

13 day, decrease in $c l d n 28 b$ and no difference for $c l d n 27 a,-28 a$ and $-30 c$. The reverse pattern was

14 observed after FW transfer of SW medaka. Intestinal cldn15a and -25 did not differ between FW

15 and SW fish. However, cldn15b was 10-fold higher in FW than SW, suggesting a role in

16 functional modulation of the intestine related to water and salt transport. In kidney, cldn10bs

17 were elevated in SW fish, suggesting a role in paracellular ion transport in the marine nephron.

18 Based on in silico analysis, most gill Cldn10s were predicted to form cation pores, whereas

19 Cldn27a, 28a, 28b and 30c may increase epithelial resistance.

20 Key words: Euryhaline teleost, Gill, Intestine, Osmoregulation, Kidney, Paracellular ion

21 transport, Tight junctions. 


\section{Introduction}

2 Euryhaline fishes generally keep their internal osmotic concentration at about the same level

3 (300-350 mOsm kg-1) after acclimating to fresh water (FW: about 1-10 mOsm kg-1) or seawater

4 (SW; about 1050 mOsm kg ${ }^{-1}$; Watts et al., 2001; Evans et al., 2005; Brauner et al., 2013) - a feat

5 accomplished by the concerted action of osmoregulatory organs, mainly gill, intestine and

6 kidney. Tight junction (TJ) strands make up the apico-lateral barrier, or gate, in between

7 epithelial cells and regulate paracellular solute and water movement (Van Itallie and Anderson,

8 2006). In the gill, TJs between adjacent pavement cells (PVCs) and mitochondrion-rich cells

9 (MRCs) are deep with multi-stranded connections (Sardet et al., 1979). In SW, shallow TJs connect neighboring MRCs and MRCs with adjacent accessory cells (ACs) suggesting a "leaky" paracellular pathway between these cells (Sardet et al., 1979). In the marine environment, branchial $\mathrm{NaCl}$ secretion involves transcellular chloride transport basolaterally by $\mathrm{Na}^{+}, \mathrm{K}^{+}, 2 \mathrm{Cl}^{-}$ cotransport and apically via cystic fibrosis transmembrane conductance regulator anion channel. This transport is secondarily coupled to the activity of $\mathrm{Na}^{+}, \mathrm{K}^{+}$-ATPase in the extensive tubular network of the MRCs (Karnaky et al., 1976). This anion transport is thought to generate a serosal positive transepithelial potential triggering sodium extrusion via a paracellular pathway ( Evans et al., 2005; Edwards and Marshall, 2012). Passive uptake of water in the gut driven by active ion uptake compensates for osmotic water loss, while the kidney's main function in SW appears to be the excretion of excess divalent ions (Flik et al., 1996; Varsamos et al., 2004; Marshall and Grosell, 2006). In FW, fish are potentially subject to extensive ion loss and osmotic water gain. The gill epithelium has no MRC complexes or ACs and is generally considered as tight with a higher electrical resistance (Sardet et al., 1979; Wilson and Laurent, 2002). The branchial epithelium actively absorbs ions and the intestinal tract also allows for some ion uptake (mainly from food uptake; Marshall and Grosell, 2006). Meanwhile, the water load is countered by renal production of a large volume of hypotonic urine (Hickman and Trump, 1969).

26 TJs are composed of proteins like claudins (Cldns), occludin, junctional adhesion molecules and tricellulin. All have four trans-membrane spanning domains, two extracellular loops (ECLs), and a cytosolic carboxy-terminal linked to the cytoskeleton through adaptor molecules like those from the zonula occludens family (Gonzalez-Mariscal et al., 2008). Proteins belonging to the Cldn super-family determine the specific permeability and ion selectivity of TJs, as demonstrated 
by over-expression of exogenous Cldns in epithelial cell cultures (Furuse et al., 1998; Van Itallie

2 et al., 2001). Furthermore, site-directed mutageneses have shown that the specific paracellular ion movement is influenced by charged amino acids (aa) of the first ECL (ECL1) and intercellular homo- or heterotypic Cldn-Cldn interaction ( Colegio et al., 2003; Angelow et al.,

5 2008). In this way, they form permeability-selective barriers critical to the function of a specific tissue. While 27 cldn genes have been described in mammals (Günzel and Yu, 2013), genomic and tandem gene duplication events have contributed to an expanded Cldn family in teleost

8 including 54-56 different genes ( Loh et al., 2004; Baltzegar et al., 2013). Cldns are often developmentally regulated and expressed in a tissue- and cell-specific manner (Loh et al., 2004; Tipsmark et al., 2008b).

In teleost gills, SW-acclimation induces elevated expression in cldn10d and cldn10e ( Tipsmark et al., 2008b; Bui et al., 2010). These paralogs are interesting candidates potentially involved in formation of a cation-selective pathway associated with $\mathrm{Na}^{+}$extrusion in $\mathrm{SW}$, especially since the homolog in mouse was shown to form cation-selective pores (Cldn-10; Günzel et al., 2009). Mouse Cldn4 appears to share a common ancestor with 13 teleost Cldns (Baltzegar et al., 2013) of which a number are highly expressed in the gill (cldn27a, cldn28a-b, cldn30c) in $\mathrm{FW}$ or in both FW and SW (Tipsmark et al., 2008a, 2008b). Of these, Cldn30c has been shown to be involved in tightening of fish epithelia (Engelund et al., 2012), similar to the barrier-forming mammalian homologs (Van Itallie et al., 2001; Yu et al., 2003).

The Japanese medaka (Oryzias latipes) is a euryhaline teleost of the ricefish family. This fish species generally lives in FW (Sakamoto et al., 2001), but is able to acclimate to full strength seawater (Inoue and Takei, 2002, 2003; Kang et al., 2008). Its euryhaline capacity combined with an evolutionary history diverging from the well-studied stenohaline zebrafish (Danio rerio), makes this species a particularly good model to study osmoregulation. Japanese medaka has the advantage of being easy to rear. Furthermore, its genome is fully sequenced and annotated, and relatively small compared to other teleosts (Tanaka, 1995). Medaka easily acclimates to salinity challenges in a manner similar to other euryhaline teleost and a recent study revealed the existence of three types of branchial ionocytes in FW and one in SW (Hsu et al., 2014). However to date, no information is available on the functional expression of $\mathrm{TJ}$ proteins in this species. 
The objectives of the present study were first to identify Cldn paralogs involved in regulation of paracellular permeability in osmoregulatory organs of Japanese medaka, with special focus on the gill. Our driving hypothesis was that fish paralogs sharing sequence similarity in the ECL1 of mammalian orthologs with barrier or ion-selective properties would respond to salinity according to the expected changes in osmoregulatory function. Based on their representation in the gill, kidney and intestine of other teleosts, 13 paralogs were pinpointed for this study. The chosen paralogs' nomenclature was examined using phylogenetic analysis and their functional properties predicted based on in silico analysis. This was followed by determination of organ distribution and expression patterns in osmoregulatory organs of fully FW- or SW-acclimated fish. Expression of cldns with high gill levels was examined during the initial stages of salinity acclimation. This was done in two transfer experiments (from FW to SW, or SW to FW) with sampling after 1 and 3 days.

\section{Materials and Methods}

\subsection{Animals}

Adult Japanese medaka (O. latipes, Temminck \& Schlegel; size range: 25-35 mm, 250-350 mg) were obtained from the Aquatic Research Organisms (Hampton, NH, USA). They were maintained in $150 \mathrm{~L}$ tanks filled with aerated de-chlorinated tap water, mechanically and biologically filtered $\left(0.34 \mathrm{mM} \mathrm{Na}^{+}, 0.64 \mathrm{mM} \mathrm{Ca}^{2+}, 0.09 \mathrm{mM} \mathrm{Mg}^{2+}, 0.03 \mathrm{mM} \mathrm{K}{ }^{+}\right)$. They were kept under a $14 \mathrm{hrs}$ light $/ 10 \mathrm{hrs}$ dark photoperiod, at $20^{\circ} \mathrm{C}$. Fish were fed 3 times per day with Tetramin Tropical flakes (Tetra, United Pet Group, Blackburg, VA, USA) or frozen brine shrimp (San Francisco Bay Brand, Inc., Newark, CA, USA). Food was withheld during the short-term salinity transfer experiments from one day before and throughout the experiment. All experiments and handling procedures were approved by the Animal Care and use Committee of the University of Arkansas (IACUC protocol number 11005).

\subsection{Experiments and sampling}

Three experiments were performed in order to examine the chosen cldns organ distribution and response to salinity. One experiment applied long-term FW-and SW-acclimated (28 ppt) fish to determine the organs levels of medaka cldns at the two conditions. Fish were acclimated for one 
month at their respective salinity prior to sampling. They were anesthetized using $100 \mathrm{mg} \mathrm{L}^{-1}$ of tricaine methanesulfonate (MS-222, buffered with $\mathrm{NaHCO}_{3}$ for $\mathrm{FW}$ ) and then killed by cervical dislocation. Gills, kidney, intestine, muscle and liver were dissected, immediately frozen on dryice and stored at $-80^{\circ} \mathrm{C}$ before further use. Samples of each organ from $\mathrm{FW}$ were used in order to determine the distribution of claudins $(N=6)$. Samples from the osmoregulatory organs (gills, kidney and intestine) were used to determine cldn expression according to salinity $(N=6)$. The initial gill response to salinity was examined in two short-term transfer experiments: fishes long-term acclimated for at least one month were transferred from FW to SW or SW to FW and sampled after 1 and 3 days. As sham controls, fish were transferred from FW to FW or SW to SW.

\subsection{Claudin nucleotide sequences, alignment and phylogenetic analysis}

The claudin targets mRNA sequences in medaka were found and identified by similarity search BLAST against known claudins of tiger pufferfish, Takifugu rubripes (Fugu), using the database GenBank (Table 1). The phylogenetic tree construction was based on maximum-likelihood analysis of putative aa sequences of medaka (Me), T. rubripes $(\mathrm{Fu})$ and mammalian (house mouse, Mus musculus, Mo), and as out-group the clarin1 from mouse (Table 2). The maximum likelihood consensus tree was generated using SEQBOOT, PROML and CONSENSE, all programs in the PHYLIP package (Felsenstein, 1989). A neighbor joining consensus tree was generated using SEQBOOT, PROTDIST, NEIGHBOR and CONSENSE also programs in the PHYLIP package. Protein sequences were aligned using ClustalW2 pairwise alignment algorithm.

\subsection{RNA isolation, cDNA synthesis and quantitative PCR (qPCR)}

Organs were homogenized in Tri reagent (Sigma-Aldrich, St. Louis, MO, USA) using a VWR PowerMax 200 rotating knife homogenizer (Advanced Homogenizing System, Manufactured by pro Scientific for Henry Troemner LLC, Thorofare, NJ, USA). Total RNA was extracted according to the manufacturer's protocol. RNA pellet was dissolved into nuclease-free water and the concentration and purity (A260/A280 ratio at least > 1.90) were estimated using a NanoDrop 2000 spectrophotometer (Thermo Fisher Scientific Inc., Waltham, MA, USA). For each sample, first strand cDNA was obtained from $1 \mu \mathrm{g}$ of total RNA using the High Capacity cDNA reverse 
transcription kit from Applied Biosystems (Foster City, CA, USA) in a final volume of $20 \mu \mathrm{L}$ and following the manufacturer's protocol. Claudins mRNA sequences used for the design of specific primers were: Me-cldn10b1, Me-cldn10b2, Me-cldn10c, Me-cldn10d, Me-cldn10e, Mecldn10f, Me-cldn15a, Me-cldn15b, Me-cldn25, Me-cldn27a, Me-cldn28a, Me-cldn28b and Mecldn30c (Table 1). All primers used in this study, including those used as reference genes for normalization (ribosomal protein $\mathrm{P} 0$, rplp0; elongation factor $1 \alpha$, efla; $\beta$-actin, $a c t b$ ), were designed using Primer-3 software (Rozen and Skaletsky, 1998) and synthesized by Sigma Aldrich. Quantitative real-time PCR (qPCR) analyses were performed using BioRad CFX96 platform thermocycler (BioRad, Hercules, CA, USA), the SYBR ${ }^{\circledR}$ Green JumpStar $^{\mathrm{TM}}$ Taq ReadyMix $^{\mathrm{TM}}$ (Sigma-Aldrich) and a primer concentration of $150 \mathrm{nM}$ each, in a final volume of $15 \mu \mathrm{L}$. The qPCR was performed with an initial heating step at $94^{\circ} \mathrm{C}$ for $2 \mathrm{~min}$, followed by 40 cycles of: denaturation step at $94^{\circ} \mathrm{C}$ for $30 \mathrm{sec}$, and an annealing/elongation step at $60^{\circ} \mathrm{C}$ for 1 min. Melting curve analysis was performed from 55 to $94^{\circ} \mathrm{C}$ with a gradient of $5 \mathrm{~s}$ per ${ }^{\circ} \mathrm{C}$ to confirm the specificity of the reaction. Standard curves were used to determine the primer sets efficiency. Relative mRNA expression was calculated according to Pfaffl's equation (Pfaffl, 2001): $C_{n}=\left(1+E_{a}\right)^{-C t}$, with $C_{n}$ the relative copy number, $C t$ the threshold cycle of the target gene and $E_{a}$ the amplification efficiency. Relative expression of target genes was normalized against the geometric means of the corrected expression data of the three normalization genes using GeNorm software (Biogazelle, Zwijnaarde, Belgium). No template controls (NTC) were always included to confirm specificity of template amplification and absence of primer-dimers.

\subsection{Statistics}

All statistical analyses were performed using GraphPad Prism 5.0 software (San Diego, CA, USA). The homogeneity of variances was tested with Bartlett's test. To meet the ANOVA assumption of homogeneity of variances, transformation of data was done when required. Organ expressions were analyzed by one-way ANOVA, followed by Tukey's Honestly Significant Difference (HSD) post-hoc test. Expression data from the short-term experiments were analyzed with two-factorial ANOVA. When a significant interaction between factors was found, this was followed by Bonferroni-adjusted Fisher's LSD pairwise comparison test and otherwise the overall effects are indicated. Results are expressed as the mean \pm standard error mean (s.e.m.) with a $\mathrm{p}$-value of $\mathrm{p}<0.05$. 


\subsection{Phylogenetic analysis}

3 Thirteen Japanese medaka Cldns were classified according to their similarity with orthologous 4 genes in Fugu. Six genes, including 2 splice variants, encoded Cldn10 proteins (Me-cldn1Ob1, -

$510 b 2,-10 c,-10 d,-10 e$ and $-10 f)$. Me-cldn10 paralogs are highly conserved in teleosts and exhibit

6 74-97\% of amino acids (aa) sequence identity compared to Fugu Cldn10's (data not shown). The

7 nomenclature of the medaka claudins was examined by constructing a maximum likelihood

8 phylogenetic tree based on the coding sequences of Fugu class II and IV Cldns (classification by

9 Loh et al. 2004; Fig. 1) and mouse Cldns. The consensus phylogenetic tree confirmed the initial

10 chosen nomenclature (Fig. 1) and a neighbor-joining analysis gave a similar result (data not

11 shown). One Cldn10 paralog was most closely related to Fugu Cldn10e but still distinctively

12 different and thus given the name Cldn10f (see Fig. 1). The tree showed that Me-Cldn10s are

13 grouped with Fugu Cldn10 homologues and mouse Cldn10 (a and b splice variant). Medaka

14 Cldn15a and b are grouped with their respective Fugu Cldn15a and b, along with mouse Cldn15.

15 Medaka Claudin27a, -28a, -28b and -30c are grouped with their respective Fugu homologue and 16 mouse Cldn3 and -4.

\section{7}

18

\subsection{In silico prediction of claudin functional properties}

The first ECL of each claudin was aligned with mammalian sequences, for which functional investigations have been undertaken in previous studies, in order to deduce putative functional role of these proteins in medaka (Fig. 2). The ECL1 consists of about 50 aa and contains positively (blue; +) and negatively (red; -) charged residues, as well as aromatic residues (aaa). Some of these amino acids are highly conserved, such as the first tryptophan residue of our alignment, which was numbered 1 for clarity. The bracket indicates the area after the 2 nd conserved Cys residues especially involved in selective permeability. Residues highlighted in yellow indicate positions essential for ion selectivity. Aromatic residues are conserved in all the claudins studied at the position 1,21, 25 and 41, with the exception of Leu21 and Ile41 for MeCldn10b2 and 10c, respectively. Me-Cldn10b1, -10d, -10e, and -10f share the same suite of residues adjacent to the second conserved Cys residue of the ECL1 (bracket area from 39-42, Fig. 2) as Mo-Cldn10b: +/-/aaa. This pattern is also found in Me-Cldn15a, -15b and -25. Me- 
Cldn10b2 however has a positive residue followed by two aaa at the position 39-42, which is similar to Mo-Cldn10a, while Me-Cldn10c only has a positive residue in this area. Furthermore, Me-Cldn10b2 shared an Arg (position 6) with Mo-Cldn10a. Finally, Cldns of mouse and teleosts of class VI shared a similar motif at 39-42 positions: +/neutral (or aaa for Me-Cldn28b)/aaa/-.

\subsection{Organ distribution}

The transcript abundance of thirteen claudins was analyzed and compared in gills, kidney and intestine as well as in liver and muscle (Fig. 3). The mRNA level of each claudin was generally distinctly higher in one particular osmoregulatory organ. The highest expression of Me-cldn10c, $-10 d,-10 e,-10 f,-27 a,-28 a,-28 b$ and $-30 c$ was found in gills (Fig. 3C-F, J-M) with levels 4 to 100-fold higher than in kidney or intestine. Me-cldn10b1 (about 14-fold the gill level) and 10b2 (about 17-fold the gill level) were mainly expressed in kidney (Fig. 3A, B). Meanwhile, Mecldn15a, -15b and -25 had 16 to 2700-fold higher expression in intestine than in the other examined organs (Fig. 3G-I). Most of the examined claudins had a very low expression in liver and muscle (Me-cldn10b1, -10b2, -10f, -15a, -15b, -25, -27a, -28a, -28b and -30c) and Mecldn10c, $-10 d$ and $-10 e$ are undetectable or barely expressed in organs other than gills.

\subsection{Claudin expression in FW and $S W$}

Each claudin was quantified in the osmoregulatory organs of fish acclimated long-term to FW vs. SW (Fig. 4). Me-cldn10c, -10d, -10e and -10f, which are found predominantly in gills, showed a significant 3-4-fold higher mRNA expression in SW than in FW (Fig. 4C-F). However, the four other claudins highly expressed in gills (Me-cldn27a, -28a, -28b, -30c) did not differ between FW and SW (Fig. 4J-M). Me-cldn15a and -25 which are mainly expressed in the intestine had similar expression in FW and SW, while $M e$-cldn15b was about 8-fold higher in FW than in SW fish (Fig. 4G-I). In the kidney, both Me-cldn1Ob splice variants (1 and 2) had elevated expression in SW fish being 3-10-fold higher than in FW (Fig. 4A, B).

Transcript expression of the claudins with dominant gill expression (Me-cldn10c, -10d, -10e, $10 f,-27 a,-28 a,-28 b$ and $-30 c$ ) was quantified in the initial acclimation stages after FW to SW transfer (Fig. 5) or SW to FW transfer (Fig. 6). SW transfer induced an overall elevation of $M e$ cldn10c, $-10 d,-10 e$ and $-10 f$ expression (Fig. 5A-D). The lack of interaction between time and 
salinity signify that the observed salinity effects are similar at 1 and 3 days. There were no significant effects on Me-cldn27a, -28a and -30c (Fig. 5E, F, H). There was an overall effect of salinity on $\mathrm{Me}$-cldn28b with reduced levels in the SW-transferred fish (Fig. 5G). After FW transfer of SW-acclimated medaka, an overall effect of salinity with reduced levels of $M e$ cldn10c, $-10 e$ and $-10 f$ expression was found. The lack of interaction between time and salinity shows that the observed salinity effects were similar after 1 and 3 days (Fig. 6A, C, D). For Me$c l d n 10 c$, there was a significant interaction between time and salinity, and reduced mRNA levels were first observed after 3 days in FW (Fig. 6B). There were no significant effects of FW transfer on Me-cldn27a, -28a and -30c (Fig. 6E, F, H). However, Me-cldn28b was elevated after 1 and 3 days (overall effect of FW).

\section{Discussion}

\subsection{Overview}

Recently, Japanese medaka has been highlighted as a good alternative model to zebrafish for osmoregulation studies and multiple proteins involved in transcellular solute and water transport have therefore been the topic of a number of studies (Kang et al., 2008; Wu et al., 2010; Lin et al., 2012; Madsen et al., 2014; Hsu et al., 2014). The expression of the TJ proteins defines the paracellular barrier and thus their involvement in overall epithelial function has yet to be examined. In the present work, 13 Cldn sequences were identified in the genome of the Japanese medaka with predicted role in osmoregulation (Chasiotis et al., 2012). The Cldns were named based on phylogenetic analyses and following the nomenclature used in other teleost species (Bagherie-Lachidan et al., 2008, 2009; Tipsmark et al., 2008a, 2008b), as outlined in Fugu (Loh et al., 2004) and Zebrafish (Baltzegar et al., 2013). Eight genes encoding for Me-Cldn10s (i.e. Me-cldn10c, -10d, -10e and -10f) and Me-Cldn27a, - 28a, -28b and -30c had the highest mRNA expression in gills. Me-cldn10b had a high level of renal expression while Me-cldn-15a, -15b and -25 were all strongly expressed in the intestine. A summary of our results and the putative role of each medaka claudin are presented in Table 3. The salinity-sensitive expression of some $\mathrm{Me}$ cldns suggests an important role in the phenotypic plasticity of the gill, kidney and intestine. 
1 The phylogenetic analysis and ECL1 alignment with known Fugu and mammalian claudins give us some insight into the potential function of the medaka Cldns. Indeed, the ECL1 creates a barrier or anion/cation pore according to its composition of charged and aromatic amino acids (see yellow highlighted residues, Fig. 2; Colegio et al., 2002; Van Itallie et al., 2003; Angelow et al., 2008; Li et al., 2013). As such, when Mo-Cldn15 D31 or/and E40 are substituted by a positive charge, the mutated protein displays a high anion permeability creating chlorideselective paracellular channels ( Colegio et al., 2002; Angelow et al., 2008). Furthermore, Li et al. (2013) demonstrated that the aromatic residue facilitates cation permeation by side chain cation- $\pi$ interaction and limits anion movement by restricting the pore size for cation-selective claudins. These studies and our alignment analysis substantiate the hypothesis that four Claudin10s in Japanese medaka (i.e. Me-Cldn10b1, -10d, -10e and -10f) and two Cldn15s are likely to be cation pore-forming proteins. Me-Cldn10b2 possesses a very similar ECL1 to Mo-Cldn10a with the same aa (position 6 and 39) which have been shown to be the only positive charges influencing chloride permeation in mammals (Van Itallie et al., 2006). Furthermore, Li et al. (2013) suggested that aaa's located after the 2nd conserved Cys in anion-selective claudins facilitate $\mathrm{Cl}^{-}$movement and create a strong steric effect, preventing $\mathrm{Na}^{+}$passage. These similarities strongly suggest that Me-Cldn10b2 could form an anion-selective pore. The function of Cldn10c and -25 in medaka is more uncertain due to mutations, in particular at position 31 and 40, respectively. However, Colegio et al. (2002) showed that D31 is sufficient to confer to the protein the cation-selective properties while D40 alone increases sodium permeability; together they have an additive effect. Claudins of class VI are orthologous to the mammalian Claudin-4 previously described as a cation barrier. Since all Me-Cldn4-like paralogs possess the same motif of aa's from position 39 to 42 which is responsible, at least in part, for the cation resistance (Colegio et al., 2002), we hypothesize that Me-Cldn27a, -28a, -28b and -30c form cation barriers. This is in agreement with their high similarity to a barrier forming paralog from Atlantic salmon and zebrafish (Engelund et al., 2012; Kwong and Perry, 2013).

\subsection{Claudins in the medaka gill}

Four $c l d n 10$ paralogs $(c, d, e$ and $f$ ) found in medaka are mainly expressed in the gills. Except for cldn10f, these TJ proteins have been detected in the gills of several euryhaline species such as Atlantic salmon (Tipsmark et al., 2008a; Tipsmark et al., 2009), rainbow trout (Kolosov et al., 
2014), Fugu (Loh et al., 2004) and spotted green pufferfish (Bui et al., 2010). All four claudins

2 were most abundantly expressed in gill of SW medaka with a response to salinity change within 1 day of exposure. Seawater also caused an elevation of Cldn10d and -10e abundance in spotted green pufferfish (Bui and Kelly, 2014) and of cldn10e levels in Atlantic salmon (Tipsmark et al., 5 2008b). In rainbow trout, cldn10c and -10d are detected only in cultured epithelium containing both PVCs and MRCs but not in PVCs-only epithelium (Kolosov et al., 2014), suggesting that these paralogs are exclusively found in association with ionocytes. Similarly, the elevated expression in SW of medaka cldn10c, 10d, 10e and $10 f$ paralogs suggest a specific role associated with cell types that proliferate in this environment. Thus, we speculate that they are essential to the functioning of SW-type MRCs. As discussed above, in silico predictions suggest that they all have the potential to form intercellular cation-selective pores. Thus, one possible role of one or more of these Cldn10 paralogs could involve sodium exit through the TJs linking ACs and MRCs.

The medaka homologues (cldn27a, $-28 a,-28 b$ and -30c) to mammalian Cldn4 are all highly expressed in gills, as previously found in Atlantic salmon (Tipsmark et al., 2008b) and is also seen in several other teleosts (Chasiotis et al., 2012). In some species, cldn27a,- 28a, -28b and $30 c$ are regulated by salinity and hormone treatments (Chasiotis et al., 2012). In Atlantic salmon, SW acclimation induces a decrease in transcript levels of cldn27a (Tipsmark et al., 2008b) and it green pufferfish after acclimation to SW (Bagherie-Lachidan et al., 2009). In medaka, no effect of salinity on branchial cldn27a expression has been seen during both initial and long-term acclimation. In Atlantic salmon and tilapia, SW-acclimation induced a decrease in cldn30c. FWacclimation induced an up-regulation of $c l d n 28 b$ in tilapia, while no overall effect on $c l d n 28 a$ and $-28 b$ were detected in Atlantic salmon (Tipsmark et al., 2008a, 2008b). In medaka, only $c l d n 28 b$ responded to salinity. This was seen during the initial 1-3 days of salinity acclimation, where a decreased expression in SW short-term mirrored an increase after FW transfer. However, no difference was detected between salinities in long-term acclimated-fish, suggesting a role of this paralog during initial gill remodeling. Thus, the regulatory expression patterns of gill Cldn4 related paralogs, as examined in the present study, may have species-specific functions possibly attributed to the ecology of the species (Tipsmark et al., 2008a, 2008b; Bagherie-Lachidan et al., 2009). The constitutive expression level of $c l d n 27 a,-28 a$ and $-30 c$ in 
medaka exposed to different salinity may suggest equal significance in FW and SW. The

2 branchial epithelium of FW fish needs to be tight to limit the constant water entry and ions loss, while SW gills secrete sodium via "leaky" tight junction located between the ACs and MRCs.

4 However, these SW ionocytes constitute only a minority of the epithelial cells ( Perry and Walsh,

5 1989; Perry and Laurent, 1993). Even in SW, more than $80 \%$ of the epithelial surface is composed of PVCs, with deep TJs in between each other and when bordering to ACs and MRCs ( Sardet et al., 1979; Evans et al., 2005). This suggests that SW gills are mainly a non-leaky epithelium which would support the need to limit water loss and ions intrusion. Our data suggests that $c l d n 27 a,-28 a$ and $-30 c$ play a role in maintaining gill integrity and tightness between pavement cells and in the deeper cell layers of the filament epithelium. Consistent with this, Cldn30c are localized at epithelial cell-cell contacts on the zebrafish larval skin (Kwong and Perry, 2013) and between both PVCs and cells deeper in the branchial filament in Atlantic salmon (Engelund et al., 2012). In both species this isoform creates cation barrier as predicted by in silico analysis. Elevated expression of cldn28b during development of cultured-epithelium

\subsection{Claudins in medaka intestine}

Medaka cldn15a, -15b and -25 were found predominantly in the intestine, with some renal cldn15a expression ( 10\% of intestinal levels). This is in accordance with previous findings in Atlantic salmon (Tipsmark et al., 2010) and zebrafish (Bagnat et al., 2007). Similarly, studies on tissue distribution in Fugu found cldn15a in intestine and kidney and cldn25 in the intestine, while $c l d n 15 b$ was below detection levels (Loh et al., 2004). In the medaka intestine, cldn15b salmon induced an up-regulation of both $c l d n 15 a$ and -25b (Tipsmark et al., 2010) and they were suggested to be involved in decreasing paracellular ionic permeability (Sundell et al., 2003; Tipsmark et al., 2010). This could, in theory, limit luminal salt loss from the lateral intercellular space and direct salt and water uptake to a transcellular route supported by elevated expression of aquaporins and $\mathrm{Na}^{+}, \mathrm{K}^{+}$-ATPase in salmonid enterocytes after SW entry (Seidelin et al., 2000; 
Madsen et al., 2011). Given the leaky nature of the intestinal epithelium in general, this does not

2 preclude a paracellular route of solute and water uptake in marine salmonids (Sundell and Sundh, 2012). In addition, zebrafish Cldn 15 functions in paracellular cation-selective transport and is critical during intestinal lumen formation (Bagnat et al., 2007). In mammalian intestine,

5 expression of Cldn2 and Cldn15 appears associated with formation of paracellular water and cation-selective pores involved in high paracellular transport-rates (Rosenthal et al., 2010; Günzel and $\mathrm{Yu}, 2013)$. The intestine of FW teleosts is involved in dietary ion uptake, while extensive uptake of $\mathrm{NaCl}$ in $\mathrm{SW}$ is thought to drive compensatory water uptake (Marshall and

\subsection{Claudins in medaka kidney}

In the present study, two cldn $10 b$ splice variants were found to be expressed mainly in the Grosell, 2006; Madsen et al., 2014). In medaka acclimated to FW, the presence of intestinal cldn15a and -25 may have an important role in hyper-osmoregulation. Furthermore, cldn15b with 10-fold higher expression in FW could be involved in paracellular cation (likely $\mathrm{K}^{+}$) transport. In rainbow trout, net transport of sodium in FW intestine is negligible, though there is a 80-90\% uptake of $\mathrm{K}^{+}$and $\mathrm{Cl}^{-}$(Bucking and Wood, 2006). In SW, a decrease in transcript level of Me-cldn15b paralog was observed. We previously showed that aquaporins located in the apical membrane have a lower expression in SW than FW (Madsen et al., 2014). This suggests that intestinal water absorption in SW depends on paracellular water flux to a higher degree than in salmonids, and could possibly be associated with the change in Me-cldn paralog composition observed in the present study. kidney, similar to Cldn10 splice variants in mammals (Angelow et al., 2008). Our study is in accordance with studies in Fugu and zebrafish showing that $c l d n 10 b$ was restricted to the kidney (Loh et al., 2004; Baltzegar et al., 2013). In FW teleosts, the distal tubule is largely water impermeable and instrumental in producing hypotonic urine to compensate ions losses. Water elimination and salt retention occur via apical $\mathrm{Na}^{+}, \mathrm{Cl}^{-}$cotransporter and $\mathrm{Na}^{+}, \mathrm{K}^{+}, 2 \mathrm{Cl}^{-}$cotranporter type 2, driven by basolateral $\mathrm{Na}^{+}, \mathrm{K}^{+}$-ATPase (Engelund and Madsen, 2011; Kato et al., 2011). In marine fishes, the primary urine is supposedly produced by glomerular filtration in combination with the secretion of $\mathrm{NaCl}$ and water into the proximal nephron segments, linked to the active secretion of $\mathrm{Mg}^{2+}$ and $\mathrm{SO}_{4}{ }^{2-}$ (Cliff and Beyenbach, 1992; Beyenbach, 2004). In the mammalian proximal tubule, the coordinated action of anion-selective and cation-selective Cldn 
1 paralogs expressed in separate segments are thought to be involved in re-uptake of filtered

2 chloride and sodium, respectively (Hou et al., 2013). While a number of studies have

3 documented expression of a series of cldn paralogs in the teleost kidney (Loh et al., 2004;

4 Baltzegar et al., 2013), the current study is to our knowledge the first to report a renal cldn

5 responding to salinity. As discussed in the in silico analysis, medaka splice variant Cldn10b1

6 shares high similarity to mammalian cation-pore forming Cldn10b. Meanwhile, medaka splice

7 variant Cldn10b2 is more similar to mammalian anion-pore forming Cldn10a (Van Itallie et al.,

8 2006; Angelow et al., 2008). It is possible that elevated expression of the two medaka cldn10b in

$9 \mathrm{SW}$ is important to paracellular $\mathrm{NaCl}$ re-absorption coupled to transcellular divalent ion secretion

10 in the proximal tubule (Beyenbach, 2004), with each splice variant having selective ion

11 selectivity.

\subsection{Conclusion and perspectives}

13 The present study of claudin proteins in osmoregulatory organs of the euryhaline medaka 14 represents the first contribution to a new area of research in this very tractable model for 15 understanding osmoregulatory physiology. We showed that putative barrier-forming claudins $16(c l d n 27 a,-28 a,-28 b$ and $-30 c)$ are constitutively expressed in the gill of long-term acclimated 17 FW and SW medaka. A series of cldn10 paralogs (cldn10c, -10d, -10e and -10f) had high gill 18 expression especially in SW suggesting a role in SW ionocyte function, including paracellular sodium extrusion. Intestinal and renal claudins with potential pore-forming capacity are regulated after long-term salinity change and thus probably involved the function of these

21 osmoregulatory epithelia. In future studies, it will be imperative to analyze protein abundance 22 and localization and to classify functional barrier and transport characteristics of the individual 23 claudin proteins.

\section{Acknowledgements}

26 The authors would like to thank Ms. R.T. Trubitt for technical help. This work was supported by

27 a grant from the National Science Foundation [IBN 12-51616] and the Arkansas Biosciences 

Commission.

\section{References}

Angelow, S., Ahlstrom, R. and Yu, A. S., 2008. Biology of claudins. Am. J. Physiol. Renal Physiol. 295, F867F876.

Bagherie-Lachidan, M., Wright, S. I. and Kelly, S. P., 2008. Claudin-3 tight junction proteins in Tetraodon nigroviridis: cloning, tissue-specific expression, and a role in hydromineral balance. Am. J. Physiol. Regul. Integr. Comp. Physiol. 294, R1638-R1647.

Bagherie-Lachidan, M., Wright, S. I. and Kelly, S. P., 2009. Claudin-8 and -27 tight junction proteins in puffer fish Tetraodon nigroviridis acclimated to freshwater and seawater. J. Comp. Physiol. B 179, 419-431.

Bagnat, M., Cheung, I. D., Mostov, K. E. and Stainier, D. Y. R., 2007. Genetic control of single lumen formation in the zebrafish gut. Nature Cell Biol. 9, 954-960.

Baltzegar, D. A., Reading, B. J., Brune, E. S. and Borski, R. J., 2013. Phylogenetic revision of the claudin gene family. Mar. Genomics 11, 17-26.

Beyenbach, K. W. (2004). Kidneys sans glomeruli. Am. J. Physiol. Renal Physiol. 286, F811-F827.

Brauner, C. J., Gonzalez, R. J. and Wilson, J. M., 2013. Extreme environments: hypersaline, alkaline, and ion-poor waters. In Fish Physiology, vol. 32 eds. S. D. McCormick A. P. Farrell and C. J. Brauner), pp. 435-476. New-York: Elsevier.

Bucking, C. and Wood, C. M., 2006. Water dynamics in the digestive tract of the freshwater rainbow trout during the processing of a single meal. J. Exp. Biol. 209, 1883-1893.

Bui, P., Bagherie-Lachidan, M. and Kelly, S. P., 2010. Cortisol differentially alters claudin isoforms in cultured puffer fish gill epithelia. Mol. Cell. Endocrinol. 317, 120-126.

Bui, P. and Kelly, S. P., 2014. Claudin-6, -10d and -10e contribute to seawater acclimation in the euryhaline puffer fish Tetraodon nigroviridis. J. Exp. Biol. 217, 1758-1767.

Chasiotis, H., Kolosov, D., Bui, P. and Kelly, S. P., 2012. Tight junctions, tight junction proteins and paracellular permeability across the gill epithelium of fishes: A review. Respir. Physiol. Neurobiol. 184, 269-281.

Cliff, W. H. and Beyenbach, K. W., 1992. Secretory renal proximal tubules in seawater- and freshwater-adapted killifish. Am. J. Physiol. Renal Physiol. 262, F108-F116.

Colegio, O. R., Van Itallie, C. M., McCrea, H. J., Rahner, C. and Anderson, J. M., 2002. Claudins create chargeselective channels in the paracellular pathway between epithelial cells. Am. J. Physiol. Cell Physiol. 283, C142-C147.

Colegio, O. R., Itallie, C. V., Rahner, C. and Anderson, J. M., 2003. Claudin extracellular domains determine paracellular charge selectivity and resistance but not tight junction fibril architecture. Am. J. Physiol. Cell Physiol. 284, C1346-C1354. 
Edwards, S. L. and Marshall, W. S., 2012. Principles and Patterns of Osmoregulation and Euryhalinity in Fishes. In Fish Physiology, vol. Volume 32 eds. S. D. McCormick A. P. Farrell and C. J. Brauner), pp. 1-44: Academic Press.

Engelund, M. B. and Madsen, S., 2011. The role of aquaporins in the kidney of euryhaline teleosts. Front. Physiol. 2.

Engelund, M. B., Yu, A. S. L., Li, J., Madsen, S. S., Færgeman, N. J. and Tipsmark, C. K., 2012. Functional characterization and localization of a gill-specific claudin isoform in Atlantic salmon. Am. J. Physiol. Regul. Integr. Comp. Physiol. 302, R300-R311.

Evans, D. H., Piermarini, P. M. and Choe, K. P., 2005. The Multifunctional Fish Gill: Dominant Site of Gas Exchange, Osmoregulation, Acid-Base Regulation, and Excretion of Nitrogenous Waste. Physiol. Rev. 85, 97-177.

Felsenstein, J., 1989. PHYLIP-Phylogeny Inference Package (version 3.2). Cladistics 5, 164-166.

Flik, G., Klaren, P. H. M., Schoenmakers, T. G. M., Bijvelds, M. J. C., Verbost, P. M. and Wendelaar Bonga, S. E., 1996. Cellular calcium transport in fish: unique and universal mechanisms. Physiol. Zool. 69, 403-417.

Furuse, M., Sasaki, H., Fujimoto, K. and Tsukita, S., 1998. A single gene product, claudin-1 or -2, reconstitutes tight junction strands and recruits occludin in fibroblasts. J. Cell Biol. 143, 391-401.

Gonzalez-Mariscal, L., Tapia, R. and Chamorro, D., 2008. Crosstalk of tight junction components with signaling pathways. Biochim. Biophys. Acta 1778, 729-756.

Günzel, D., Stuiver, M., Kausalya, P. J., Haisch, L., Krug, S. M., Rosenthal, R., Meij, I. C., Hunziker, W., Fromm, M. and Müller, D., 2009. Claudin-10 exists in six alternatively spliced isoforms that exhibit distinct localization and function. J. Cell Sci. 122, 1507-1517.

Günzel, D. and Yu, A. S. L., 2013. Claudins and the Modulation of Tight Junction Permeability. Physiol. Rev. 93, 525-569.

Hickman, C. B. and Trump, B. F., 1969. The kidney. In Fish Physiology, vol. 8 eds. W. S. Hoar and D. J. Randall), pp. 91-239. New York: Academic press.

Hou, J., Rajagopal, M. and Yu, A. S. L., 2013. Claudins and the Kidney. Annu. Rev. Physiol. 75, 479-501.

Hsu, H.-H., Lin, L.-Y., Tseng, Y.-C., Horng, J.-L. and Hwang, P.-P., 2014. A new model for fish ion regulation: identification of ionocytes in freshwater- and seawater-acclimated medaka (Oryzias latipes). Cell Tissue Res. 357, 225-243.

Inoue, K. and Takei, Y., 2002. Diverse Adaptability in Oryzias Species to High Environmental Salinity. Zool. Sci. $19,727-734$.

Inoue, K. and Takei, Y., 2003. Asian medaka fishes offer new models for studying mechanisms of seawater adaptation. Comp. Biochem. Physiol. B 136, 635-645.

Kang, C.-K., Tsai, S.-C., Lee, T.-H. and Hwang, P.-P., 2008. Differential expression of branchial $\mathrm{Na}^{+} / \mathrm{K}^{+}$-ATPase of two medaka species, Oryzias latipes and Oryzias dancena, with different salinity tolerances acclimated to fresh water, brackish water and seawater. Comp. Biochem. Physiol. A 151, 566-575. 
Karnaky, K. J., Jr Kinter, L. B., Kinter, W. B. and Stirling, C. E., 1976. Teleost chloride cell. II. Autoradiographic localization of gill Na,K-ATPase in killifish, Fundulus heteroclitus, adapted to low and high salinity environments. J. Cell Biol. 70, 157-177.

Kato, A., Muro, T., Kimura, Y., Li, S., Islam, Z., Ogoshi, M., Doi, H. and Hirose, S., 2011. Differential expression of $\mathrm{Na}^{+}-\mathrm{Cl}^{-}$cotransporter and $\mathrm{Na}^{+}-\mathrm{K}^{+}-\mathrm{Cl}^{-}$cotransporter 2 in the distal nephrons of euryhaline and seawater pufferfishes. Am. J. Physiol. Regul. Integr. Comp. Physiol. 300, R284-R297.

Kolosov, D., Chasiotis, H. and Kelly, S. P., 2014. Tight junction protein gene expression patterns and changes in transcript abundance during development of model fish gill epithelia. J. Exp. Biol. 217, 1667-81.

Kwong, R. W. M. and Perry, S. F., 2013. The tight junction protein claudin-b regulates epithelial permeability and sodium handling in larval zebrafish, Danio rerio. Am. J. Physiol. Regul. Integr. Comp. Physiol. 304, R504R513.

Li, J., Zhuo, M., Pei, L. and Yu, A. S. L., 2013. Conserved Aromatic Residue Confers Cation Selectivity in Claudin2 and Claudin-10b. J. Biol. Chem. 288, 22790-22797.

Lin, C.-C., Lin, L.-Y., Hsu, H.-H., Thermes, V., Prunet, P., Horng, J.-L. and Hwang, P.-P., 2012. Acid secretion by mitochondrion-rich cells of medaka (Oryzias latipes) acclimated to acidic freshwater. Am. J. Physiol. Regul. Integr. Comp. Physiol. 302, R283-R291.

Loh, Y. H., Christoffels, A., Brenner, S., Hunziker, W. and Venkatesh, B., 2004. Extensive expansion of the claudin gene family in the teleost fish, Fugu rubripes. Genome Res. 14, 1248-1257.

Madsen, S. S., Olesen, J. H., Bedal, K., Engelund, M. B., Velasco-Santamaría, Y. M. and Tipsmark, C. K., 2011. Functional characterization of water transport and cellular localization of three aquaporin paralogs in the salmonid intestine. Front. Physiol. 2, 56.

Madsen, S. S., Bujak, J. and Tipsmark, C. K., 2014. Aquaporin expression in the Japanese medaka (Oryzias latipes, Temminck \& Schlegel) in FW and SW: challenging the paradigm for intestinal water transport? J. Exp. Biol. 217, 3108-3121.

Marshall, W. S. and Grosell, M., 2006. Ion transport, osmoregulation, and acid-base balance. In The physiology of fishes, eds. D. H. Evans and J. B. Claiborne), pp. 177-210. Boca Raton: Taylor and Francis Group.

Perry, S. F. and Walsh, P. J., 1989. Metabolism of isolated fish gill cells: contribution of epithelial chloride cells. J. Exp. Biol. 144, 507-520.

Perry, S. F. and Laurent, P. L., 1993. Environmental effects on fish gill structure and function. In Fish Ecophysiology, eds. J. C. Rankin and F. B. Jensen), pp. 231-264. London: Chapman \& Hall.

Pfaffl, M. W., 2001. A new mathematical model for relative quantification in real-time RT-PCR. Nucleic Acids Res. 29, e45-e45.

Rosenthal, R., Milatz, S., Krug, S. M., Oelrich, B., Schulzke, J.-D., Amasheh, S., Günzel, D. and Fromm, M., 2010. Claudin-2, a component of the tight junction, forms a paracellular water channel. J. Cell Sci. 123, 19131921.

Rozen, S. and Skaletsky, H. J., 1998. Primer3. Source code avalaible at http://sourceforge.net/projects/primers3. 
Sakamoto, T., Kozaka, T., Takahashi, A., Kawauchi, H. and Ando, M. 2001. Medaka (Oryzias latipes) as a model for hypoosmoregulation of euryhaline fishes. Aquaculture 193, 347-354.

Sandbichler, A. M., Farkas, J., Salvenmoser, W. and Pelster, B., 2011. Cortisol affects tight junction morphology between pavement cells of rainbow trout gills in single-seeded insert culture. J. Comp. Physiol. B 181, 1023-1034.

Sardet, C., Pisam, M. and Maetz, J., 1979. The surface epithelium of teleostean fish gills. Cellular and junctional adaptations of the chloride cell in relation to salt adaptation. J. Cell Biol. 80, 96-117.

Seidelin, M., Madsen, S. S., Blenstrup, H. and Tipsmark, C. K., 2000. Time-Course Changes in the Expression of $\mathrm{Na}^{+}, \mathrm{K}^{+}$-ATPase in Gills and Pyloric Caeca of Brown Trout (Salmo trutta) during Acclimation to Seawater. Physiol. Biochem. Zool. 73, 446-453.

Sundell, K., Jutfelt, F., Agustsson, T., Olsen, R. E., Sandblom, E., Hansen, T. and Bjornsson, B. T., 2003. Intestinal transport mechanisms and plasma cortisol levels during normal and out-of-season parr-smolt transformation of Atlantic salmon, Salmo salar. Aquaculture 222, 265-285.

Sundell, K. and Sundh, H., 2012. Intestinal fluid absorption in anadromous salmonids: importance of tight junctions and aquaporins. Front. Physiol. 3.

Tanaka, M., 1995. Characteristics of medaka genes and their promoter regions. Fish Biol. J. Medaka 7, 11-14.

Tipsmark, C. K., Baltzegar, D. A., Ozden, O., Grubb, B. J. and Borski, R. J., 2008a. Salinity regulates claudin mRNA and protein expression in the teleost gill. Am. J. Physiol. Regul. Integr. Comp. Physiol. 294, R1004-R1014.

Tipsmark, C. K., Kiilerich, P., Nilsen, T. O., Ebbesson, L. O. E., Stefansson, S. O. and Madsen, S. S., 2008b. Branchial expression patterns of claudin isoforms in Atlantic salmon during seawater acclimation and smoltification. Am. J. Physiol. Regul. Integr. Comp. Physiol. 294, R1563-R1574.

Tipsmark, C. K., Jørgensen, C., Brande-Lavridsen, N., Engelund, M., Olesen, J. H. and Madsen, S. S., 2009. Effects of cortisol, growth hormone and prolactin on gill claudin expression in Atlantic salmon. Gen. Comp. Endocrinol. 163, 270-277.

Tipsmark, C. K., Sørensen, K. J., Hulgard, K. and Madsen, S. S., 2010. Claudin-15 and -25b expression in the intestinal tract of Atlantic salmon in response to seawater acclimation, smoltification and hormone treatment. Comp. Biochem. Physiol. A 155, 361-370.

Van Itallie, C., Rahner, C. and Anderson, J. M., 2001. Regulated expression of claudin-4 decreases paracellular conductance through a selective decrease in sodium permeability. J. Clin. Invest. 107, 1319-1327.

Van Itallie, C. M., Fanning, A. S. and Anderson, J. M., 2003. Reversal of charge selectivity in cation or anionselective epithelial lines by expression of different claudins. Am. J. Physiol. Renal Physiol. 285, F1078F1084. 429. 
Van Itallie, C., Rogan, S., Yu, A., Vidal, L.S., Holmes, J., Anderson, J.M., 2006. Two splice variants of claudin-10 in the kidney create paracellular pores with different ion selectivites. Am. J. Physiol. Renal Physiol. 291, F1288-F1299.

4 Varsamos S., Wendelaar Bonga, S.E., Charmantier, G. and Flik, G., 2004. Drinking and Na ${ }^{+} / \mathrm{K}^{+}$-ATPase activity during early development of European sea bass, Dicentrarchus labrax: Ontogeny and short-term regulation following acute salinity changes. J. Exp. Mar. Biol. Ecol. 311, 189-200.

Watts, J., Swan, B., Tiffany, M. and Hurlbert, S., 2001. Thermal, mixing, and oxygen regimes of the Salton Sea, California, 1997-1999. Hydrobiologia 466, 159-176.

9 Wilson, J. M. and Laurent, P., 2002. Fish gill morphology: inside out. J. Exp. Zool. 293, 192-213. dependent sodium uptake in mitochondrion-rich cells of medaka (Oryzias latipes) larvae. Am. J. Physiol. Cell Physiol. 298, C237-C250.

13 Yu, A. S. L., Enck, A. H., Lencer, W. I. and Schneeberger, E. E., 2003. Claudin-8 Expression in Madin-Darby Canine Kidney Cells Augments the Paracellular Barrier to Cation Permeation. J. Biol. Chem. 278, 1735017359. 
1 Table 1: Quantitative PCR primers used to detect cldn transcript levels in Japanese medaka 2 (Oryzias latipes).

\begin{tabular}{|c|c|c|c|}
\hline Target name & NCBI Acc. No. & Forward primer & Reverse primer \\
\hline Me-cldn10b1 & XM_004081778.1 & gagatcgtggctttcgttgt & tcattggacgacactttcca \\
\hline Me-cldn10b2 & XM_004081779.1 & cgccattattggtgctacag & ggcatttccagcacagtttt \\
\hline Me-cldn10c & XM_004081941.1 & cggatcaattttggtcttgg & gcgcagattcctcctacaag \\
\hline Me-cldn10d & XM_004066669.1 & ccaccgccaactactactcc & atgcaggaacaccggtagag \\
\hline Me-cldn10e & XM_004066670.1 & caaagtggcctggtactggt & tggatgttgaggtccacaga \\
\hline Me-cldn1Of & XM_004081942.1 & atcaaggtggcctggtactg & gagaaccgcgtaatctctgc \\
\hline Me-cldn $15 a$ & XM_004079825.1 & tgtcctcaaagggaggattg & tgatgttgaaggcgtaccag \\
\hline Me-cldn15b & XM_004076466.1 & caacatcacgcagcagttct & aaacctccacagatggcaag \\
\hline Me-cldn 25 & XM_004078759.1 & caagaagggcggatactttg & aggctctggatgactctgga \\
\hline Me-cldn27a & XM_004075237.1 & catgtgcatcatctccatcc & gctttggacttctcgtggtc \\
\hline Me-cldn28a & XM_004075235.1 & accgaaagcccagagtatcc & ggccgctattgtaggacttg \\
\hline$M e-c l d n 28 b$ & XM_004076181.1 & ggtcacagccttcattggat & tgcatctgccetgtactctg \\
\hline$M e-c l d n 30 c$ & XM_004076176.1 & cagccctctcctgagtaacg & ctccaatcagcatcagagca \\
\hline
\end{tabular}


1 Table 2: Amino acid sequences from house mouse (Mus musculus) and tiger pufferfish 2 (Takifugu rubripes), used to make the phylogenetic tree and the alignment analysis.

\begin{tabular}{|c|c|c|}
\hline Species & Name & Gene Bank accession number \\
\hline \multirow{6}{*}{ Mus musculus } & Cldn3 & NM_009902.4 \\
\hline & Cldn4 & NM_009903.2 \\
\hline & Cldn10a & NM_023878.3 \\
\hline & Cldn $10 \mathrm{~b}$ & NM_021386.4 \\
\hline & Cldn 15 & BC023428.1 \\
\hline & ClarinI & BC145202.1 \\
\hline \multirow{23}{*}{ Takifugu rubripes } & Cldn10a & AY554359.1 \\
\hline & Cldn $10 \mathrm{~b}$ & AY554396.1 \\
\hline & Cldn10c & AY554395.1 \\
\hline & Cldn10d & AY554391.1 \\
\hline & Cldn10e & AY554392.1 \\
\hline & Cldn15a & AY554365.1 \\
\hline & Cldn $15 b$ & AY554357.1 \\
\hline & Cldn25 & AY554364.1 \\
\hline & Cldn26 & AY554363.1 \\
\hline & Cldn27a & AY554381.1 \\
\hline & Cldn27b & AY554382.1 \\
\hline & Cldn27c & AY554370.1 \\
\hline & Cldn27d & AY554374.1 \\
\hline & Cldn28a & AY554383.1 \\
\hline & Cldn28b & AY554375.1 \\
\hline & Cldn28c & AY554373.1 \\
\hline & Cldn29a & AY554372.1 \\
\hline & Cldn29b & AY554371.1 \\
\hline & Cldn30a & AY554380.1 \\
\hline & Cldn30b & AY554384.1 \\
\hline & Cldn30c & AY554369.1 \\
\hline & Cldn30d & AY554376.1 \\
\hline & Cldn31 & AY554351.1 \\
\hline
\end{tabular}


1 Table 3: Summary of significant effects of salinity on claudin transcript levels in gill, intestine, 2 and kidney. For short-term transfer experiments, upward and downward arrows indicate up- or 3 down-regulation of transcript levels and horizontal arrows indicate no significant effect. The 4 putative function indicated is based on in silico analysis as seen in Fig. 2.

\begin{tabular}{|c|c|c|c|c|c|}
\hline & Paralog & Long-term acclimation & $\begin{array}{l}\text { Short-term } \\
\text { FW to SW }\end{array}$ & $\begin{array}{l}\text { Short-term } \\
\text { SW to FW }\end{array}$ & Putative function \\
\hline \multirow{8}{*}{ Gill } & cldn-10c & $\mathrm{FW}<\mathrm{SW}$ & $\pi$ & $\searrow$ & Cation pore-forming? \\
\hline & cldn-10d & $\mathrm{FW}<\mathrm{SW}$ & $\pi$ & $y$ & Cation pore-forming \\
\hline & cldn-10e & $\mathrm{FW}<\mathrm{SW}$ & $\pi$ & $y$ & Cation pore-forming \\
\hline & cldn-10f & $\mathrm{FW}<\mathrm{SW}$ & $\pi$ & $y$ & Cation pore-forming \\
\hline & cldn-27a & $\mathrm{FW} \sim \mathrm{SW}$ & $\rightarrow$ & $\rightarrow$ & Barrier \\
\hline & cldn-28a & $\mathrm{FW} \sim \mathrm{SW}$ & $\rightarrow$ & $\rightarrow$ & Barrier \\
\hline & cldn-28b & $\mathrm{FW} \sim \mathrm{SW}$ & $y$ & $\pi$ & Barrier \\
\hline & cldn-30c & $\mathrm{FW} \sim \mathrm{SW}$ & $\rightarrow$ & $\rightarrow$ & Barrier \\
\hline \multirow{3}{*}{ Intestine } & cldn-15a & $\mathrm{FW} \sim \mathrm{SW}$ & & & Cation pore-forming \\
\hline & cldn-15b & FW > SW & & & Cation pore-forming \\
\hline & cldn-25 & $\mathrm{FW} \sim \mathrm{SW}$ & & & Cation pore-forming? \\
\hline \multirow{2}{*}{ Kidney } & cldn-10b1 & $\mathrm{FW}<\mathrm{SW}$ & & & Cation pore-forming \\
\hline & cldn-10b2 & $\mathrm{FW}<\mathrm{SW}$ & & & Anion pore-forming \\
\hline
\end{tabular}


2 Figure 1. Consensus phylogenetic tree of claudins in the Japanese medaka. The tree was 3 generated using claudin aa sequences from medaka (Me, green), Fugu (Fu, blue) and mouse (Mo, yellow).

5 Claudin genes classes used in Loh et al. (2004) were mentioned, based on the origin and

6 phylogenetic relationships. The bootstrap consensus tree was inferred from 1000 replicates and 7 values $>70 \%$ are given.

Figure 2. Alignment of the 1st extracellular loop (ECL1) of claudins in the Japanese medaka (Me, grey) and mouse (Mo). Aa residues are highlighted in red when acidic, in blue when basic. The bracket indicates area after the 2nd Cys residues particularly involved into selective permeability. Residues yellow highlighted indicate position essential for ion selectivity (for more information, see: Angelow et al., 2008; Li et al., 2013) *: identical residue; :: conserved residue; .: semi-conserved residue.

Figure 3. Claudins transcript abundance in various organs from Japanese medaka in FW (cldn10b1, A; cldn10b2, B; cldn10c, C; cldn10d, D; cldn10e, E; cldn10f, F; cldn15a, G; cldn15b, H; cldn25, I; cldn27a, J; cldn28a, K; cldn28b, L; cldn30c, M). The expression of each claudins in kidney, intestine, muscle and liver are expressed in $\%$ of the gill abundance. Bars represent the mean value \pm s.e.m. $(N=4)$. Expression levels were normalized against the geometric mean of three normalization genes. Shared letters above the bars indicate not significantly difference in expression between organs (n.d. indicates no detection).

Figure 4. Claudins transcript abundance in the osmoregulatory organs of Japanese medaka long-term acclimated to either FW or SW (cldn10b1, A; cldn10b2, B; cldn10c, C; cldn10d, D; cldn10e, E; cldn10f, F; cldn15a, G; cldn15b, H; cldn25, I; cldn27a, J; cldn28a, $\mathrm{K} ;$ cldn28b, L; cldn30c, M).

The expression of each claudin is expressed in \% of FW gill abundance. Bars represent the mean value \pm s.e.m. $(N=6)$. of fish acclimated to either FW or SW. Expression levels were normalized against the geometric mean of three normalization genes. Asterisks above the bars 
1 indicate significant differences compared to the FW-gill expression: **: $\mathrm{p}<0.01$ and *: $\mathrm{p}<0.05$

2 (n.d. indicates no detection). FW: fresh water; SW: seawater.

3 Figure 5. Response in transcript abundance of prevailing branchial claudin paralogs, to

4 FW-to-SW transfer at short-term in Japanese medaka (cldn10c, A; cldn10d, B; cldn10e, C;

5 cldn10f, D; cldn27a, E; cldn28a, F; cldn28b, G; cldn30c, H).

6 Fish were transferred from FW to SW or FW to FW as a control and gills were sampled after 1

7 and 3 days $(N=10)$. The expression of each claudin is expressed in $\%$ of $\mathrm{FW}$ gill abundance.

8 Bars represent the mean value + s.e.m. Expression levels were normalized against the geometric

9 mean of three normalization genes. Asterisks next to SW indicate significant overall effect of

10 salinity: ***: $\mathrm{p}<0.001, * *$ : $\mathrm{p}<0.01$. FW: fresh water; SW: seawater.

11 Figure 6. Response in transcript abundance of prevailing branchial claudin paralogs, to

12 SW-to-FW transfer at short-term in Japanese medaka.

13 Fish were transferred from SW to FW or SW to SW as a control and gills were sampled after 1

14 and 3 days $(N=10)$. The expression of each claudin is expressed in \% of SW gill abundance.

15 Bars represent the mean value + s.e.m. Expression levels were normalized against the geometric

16 mean of three normalization genes. Asterisks next to FW indicate significant overall effect of

17 salinity: ***: $\mathrm{p}<0.001, * *: \mathrm{p}<0.01$ and $*$ : $\mathrm{p}<0.05$. FW: fresh water; SW: seawater. 


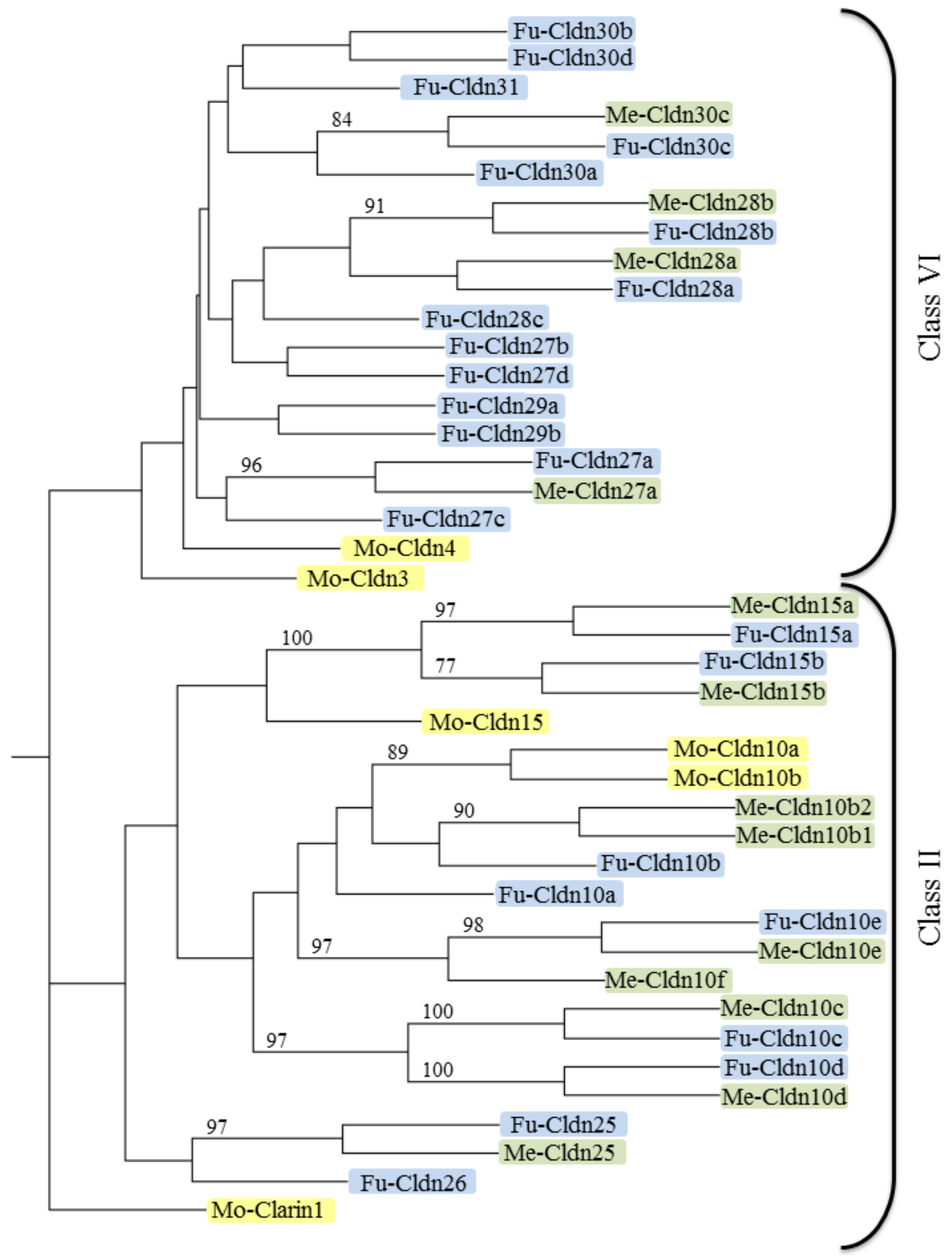




\section{$1 \quad$ Figure 2}

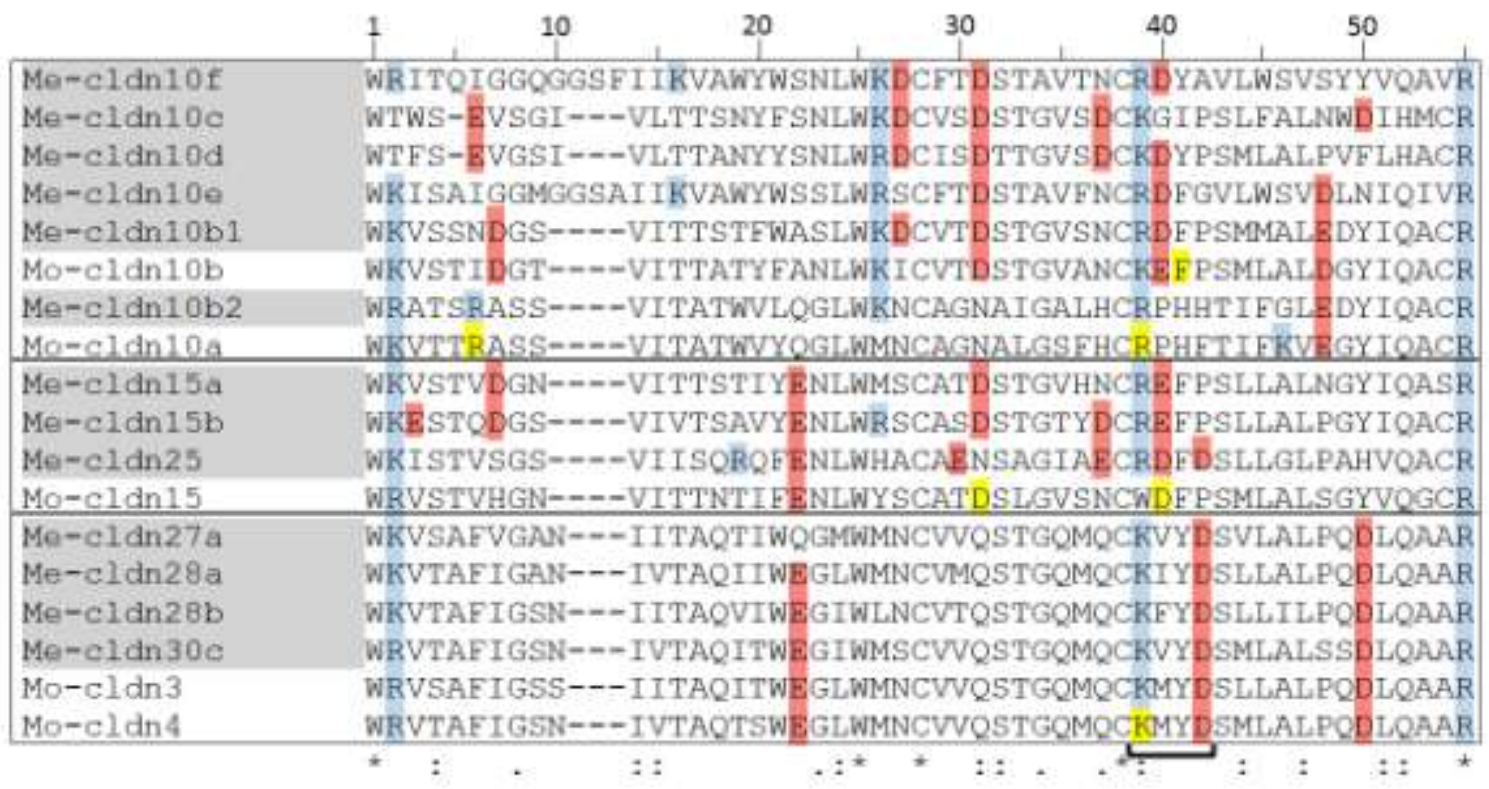



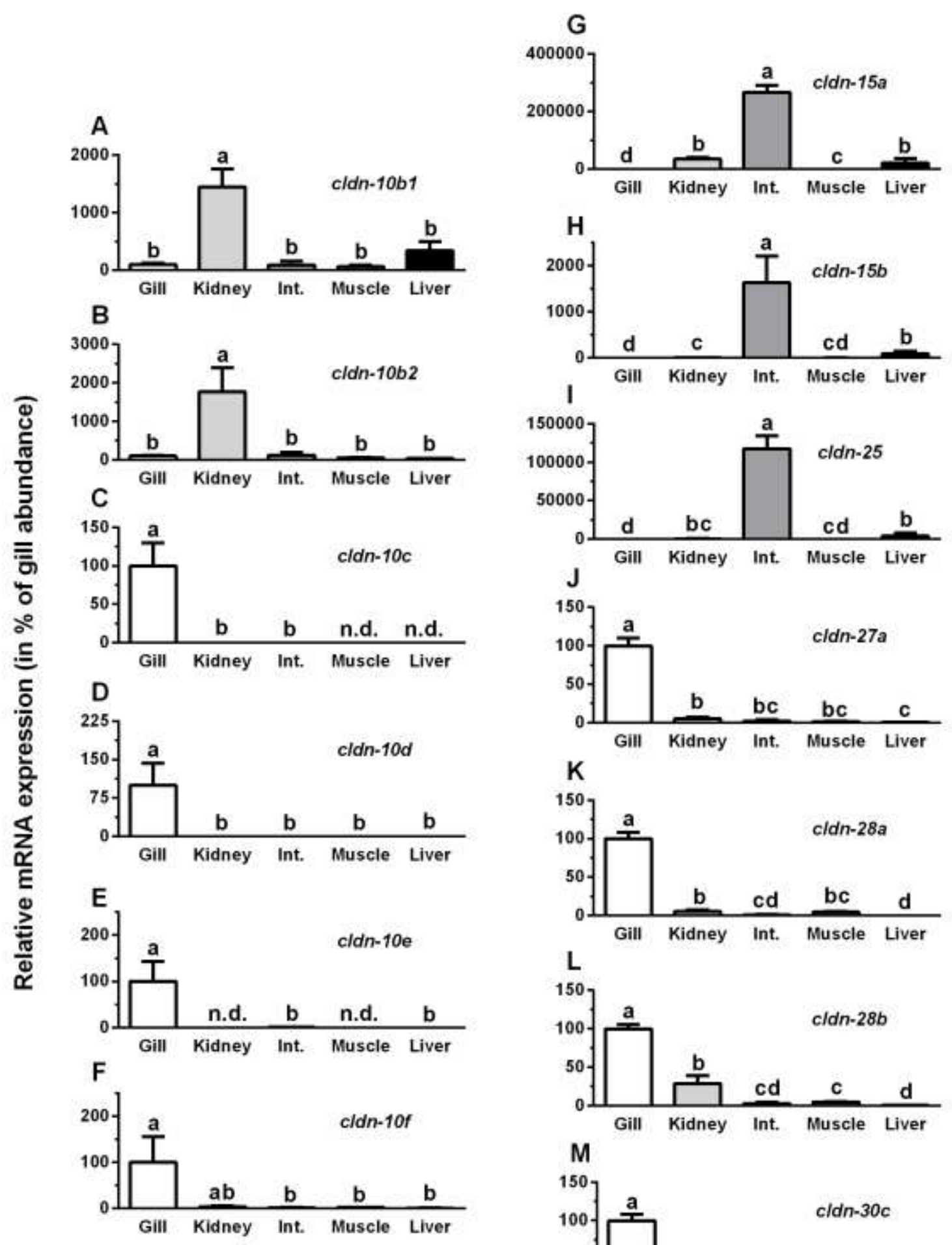

L
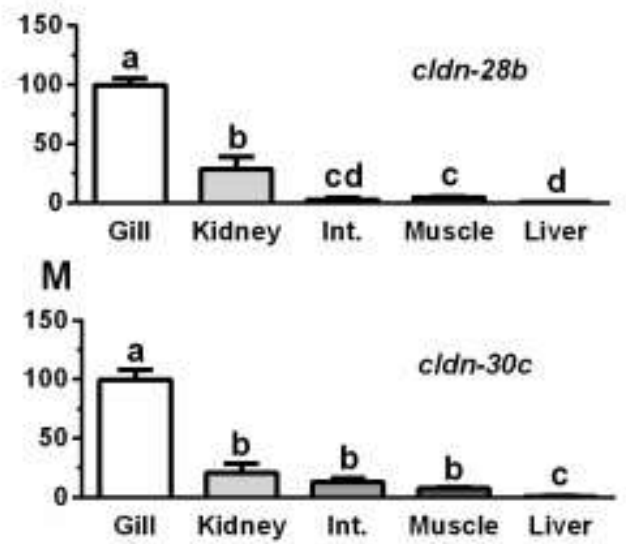


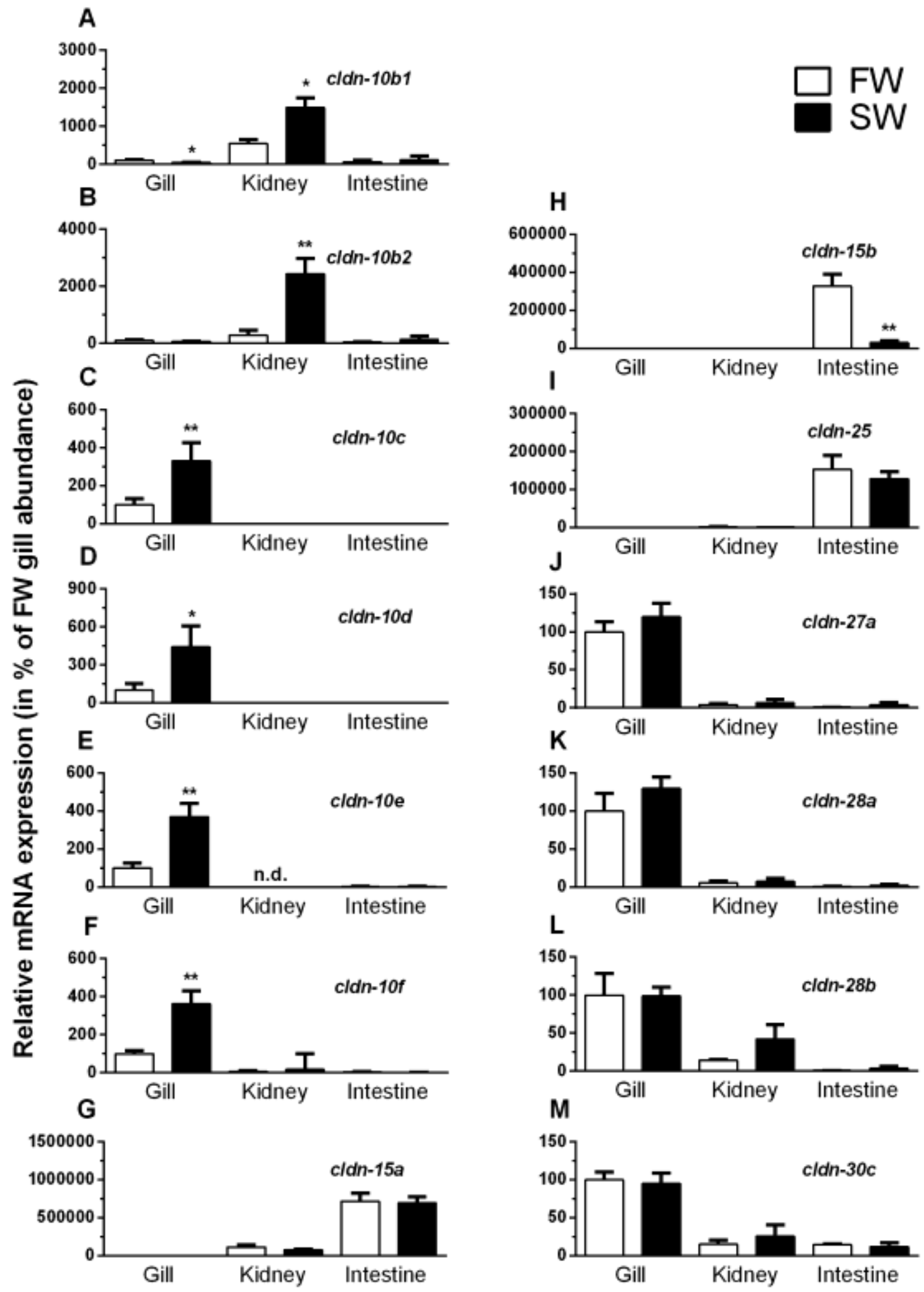



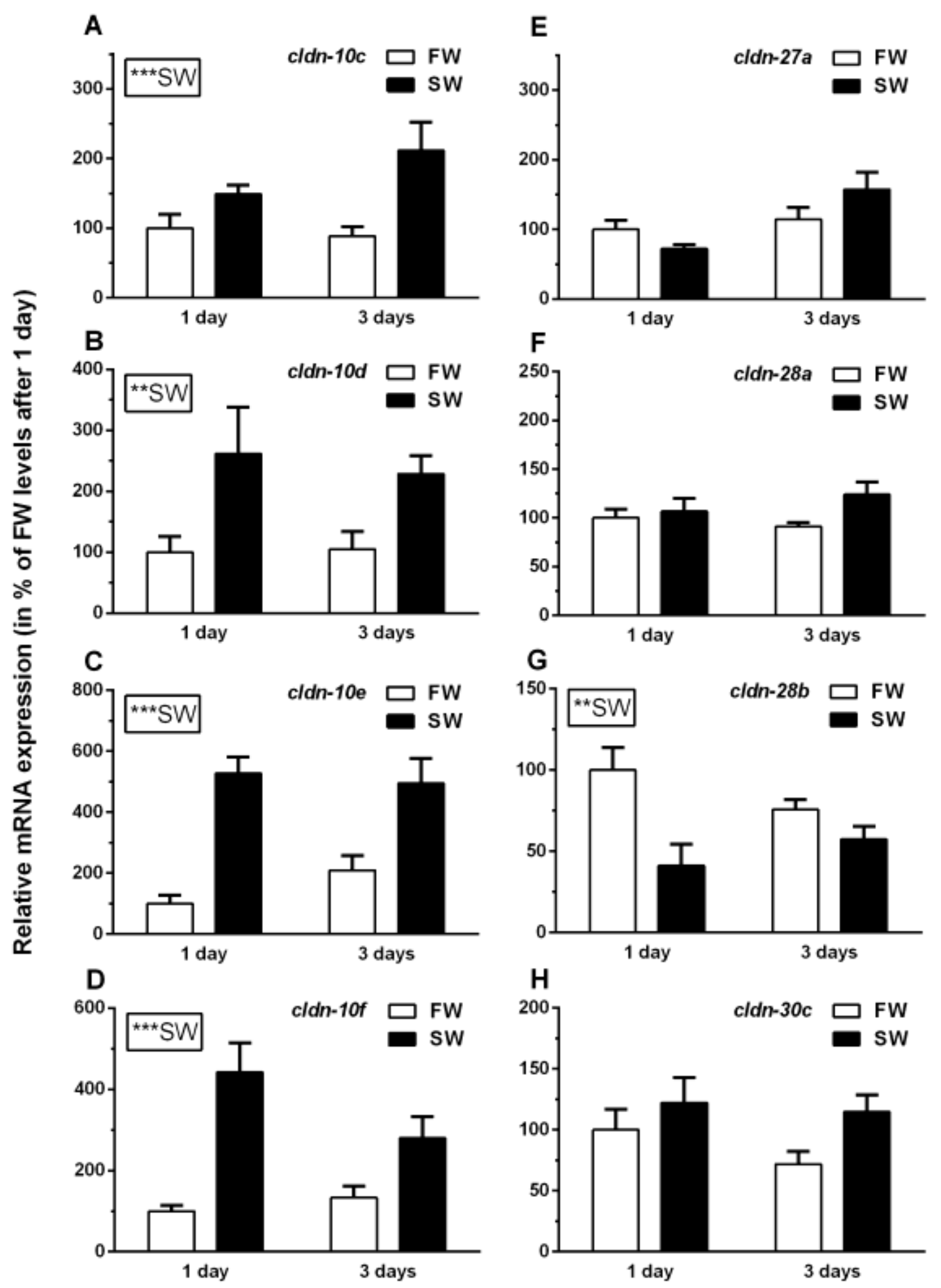

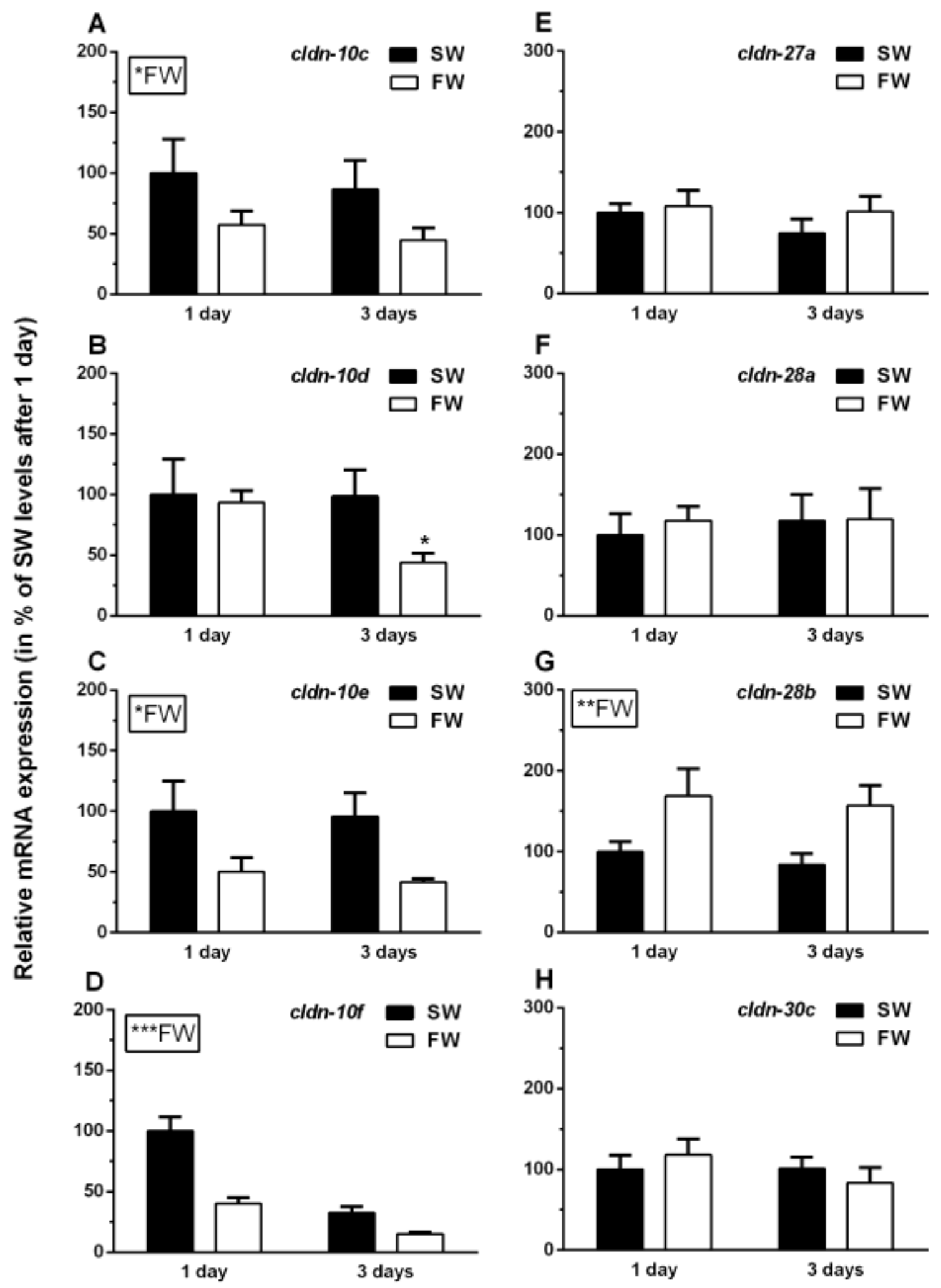